\title{
Approximate integration through remarkable points using the Intermediate Value Theorem
}

\author{
Integración aproximada mediante puntos notables usando el Teorema de Valor \\ Intermedio
}

\author{
J. Castro-Pérez ; G. P. Aguilar-Sánchez ; A. González-Nucamendi iD
}

\begin{abstract}
Using the Intermediate Value Theorem we demonstrate the rules of Trapeze and Simpson's. Demonstrations with this approach and its generalization to new formulas are less laborious than those resulting from methods such as polynomial interpolation or Gaussian quadrature. In addition, we extend the theory of approximate integration by finding new approximate integration formulas. The methodology we used to obtain this generalization was to use the definition of the integral defined by Riemann sums. Each Riemann sum provides an approximation of the result of an integral. With the help of the Intermediate Value Theorem and a detailed analysis of the Middle Point, Trapezoidal and Simpson Rules we note that these rules of numerical integration are Riemann sums. The results we obtain with this analysis allowed us to generalize each of the rules mentioned above and obtain new rules of approximation of integrals. Since each of the rules we obtained uses a point in the interval we have called them according to the point of the interval we take. In conclusion we can say that the method developed here allows us to give new formulas of numerical integration and generalizes those that already exist.
\end{abstract}

Index Terms-Approximate Integration, Simpson's Rule, Trapezoidal Rule, Middle Point Rule, Intermediate Value Theorem.

Resumen-Utilizando el Teorema de Valor Intermedio mostramos que las reglas del Trapecio y la de Simpson son ciertas sumas de Riemann. La técnica con este enfoque nos permite obtener nuevas fórmulas que resultan menos laboriosas que las que se utilizan con métodos como el de interpolación de polinomios o el de las cuadraturas de Gauss. Además, con esta técnica ampliamos el panorama de la integración aproximada al encontrar nuevas fórmulas de esta forma de integrar. La metodología que usamos para obtener dicha generalización fue utilizar de la definición de la integral definida mediante sumas de Riemann. Cada suma de Riemann proporciona una aproximación del resultado de una integral. Con la ayuda del Teorema del valor medio y un análisis detallado de las reglas del punto medio, trapecio y Simpson notamos que estas reglas de

Este manuscrito fue enviado el 04 de mayo de 2019 y aceptado el 13 de marzo de 2020.

J. Castro-Pérez is with the Instituto Tecnológico y de Estudiso Superiores de Monterrey CDMX 14380 México (e-mail: jcastrop@tec.mx).

G. P. Aguilar-Sánchez is with the Instituto Tecnológico y de Estudiso Superiores de Monterrey CDMX 14380 México (e-mail: gerardo.aguilar@tec.mx)

A. González-Nucamendi is with the Instituto Tecnológico y de Estudiso Superiores de Monterrey CDMX 14380 México (e-mail: anucamen@tec.mx) integración numérica son sumas de Riemann. Los resultados que obtenemos con este análisis nos permitieron generalizar cada una de las reglas antes mencionadas y obtener nuevas reglas de aproximación de integrales. Ya que cada una de las reglas que obtuvimos utiliza un punto en el intervalo las hemos llamado de acuerdo con el punto del intervalo que tomamos. Como conclusión podemos decir que el método que se desarrolla aquí permite dar nuevas fórmulas de integración numérica $y$ generaliza las que ya existen.

Palabras claves-Integración Aproximada, Regla de Simpson, Regla del trapecio, Regla del punto medio, Teorema del valor Intermedio.

\section{INTRODUCTION}

$\mathrm{A}$ PPROXIMATE integration methods or numerical methods are the alternative to calculate definite integrals when the primitive integrand is not known. The Mean Point, Trapeze and Simpson's rules are the methods that are usually taught in basic level courses [1], [2]. Each one of them employs a simple formula, therefore it is successful. The efficiency of the method employed, understood as the relationship between computational effort and the size of the error, depends on how rightly such method fits the given function. The more efficient, the better the method will be, but pedagogically it also matters its simplicity and intuitive clarity.

The approximations usually employ polynomials that coincide in a certain number of points with the original function, such is the case of Lagrange's polynomials. When the interpolation is done using points equally separated in the integration interval the so-called Newton Cotes Formulas are obtained, whose best-

known examples are the Mean Point rule, Trapeze rule, Simpson 3 rule, Simpson 3/8 rule or Boole rule, that use polynomials of degrees $0,1,2,3$ and 4 respectively.

An alternative focus of the interpolation polynomials is the use of the Intermediate Value Theorem (IVT) in the Riemann sums [3]. With this new focus we can deduct as particular cases the Trapeze and Simpson rules but when we generalize, we obtain formulas different from Simpson 3/8, Boole's, etc. 
In the following section we start by stating an IVT version that we will use for our deductions. In the A. subsection we will use an approach that we have called Arithmetic Mean Approach with which we deduce the Trapeze rule and the traditional Simpson rule also called Simpson 1/3. With such approach we could generate new formulas immediately. In the subsection B. we notice that is not necessary to use the arithmetic mean to generate the special point of which the IVT talks about, such point could be generated from any other point that is within the subinterval of interest such as the Geometric Mean, the Harmonic Mean, or in general, any other point obtained by a convex combination of the extreme values of the subinterval of interest.

\section{METHOD}

To deduce new approximate integration rules, we can use the next theorem that follows as an immediate consequence of the Intermediate Value Theorem.

\section{Intermediate Value Theorem.}

If $f$ denotes a continuous function over an interval $[a, b]$ such that $f(a) \neq f(b)$ and if $N$ is any number between $f(a)$ and $f(b)$, then there is at least one number $c$ between $a$ and $b$ such that $f(c)=N$.

An immediate consequence of the Intermediate Value Theorem is the following

Corollary. If $f$ is a continuous function in the interval $[a, b]$, then $f$ takes all the values between its minimum value $f(\alpha)$ and its maximum value $f(\beta)$ in the interval $[a, b]$. Where $\alpha, \beta$ belong to the interval $[a, b]$.

Notice that the minimum and maximum value of the $f$ function is guaranteed by the function continuity in the closed interval $[a, b]$.

\section{A. Formulas based on Arithmetic Mean}

Suppose that $f$ is continuous over $[a, b]$. To approximate $\int_{a}^{b} f(x) d x$, it is given a partition of the interval $[a, b]$ in $n$ subintervals of the same length: $a=x_{0}<x_{1}<x_{2}<\cdots<$ $x_{n}=b$. We know that $\sum_{i=1}^{n} f\left(x_{i}^{*}\right) \Delta x$ is a Riemann sum where $\Delta x=\frac{b-a}{n}$ and $x_{i}^{*} \in\left[x_{i-1}, x_{i}\right]$ for $i=1,2,3, \ldots, n$, therefore $\int_{a}^{b} f(x) d x \cong \sum_{i=1}^{n} f\left(x_{i}^{*}\right) \Delta x \ldots$...(1)

This approximation is known as the Left Rule

Next, we describe different alternatives to calculate the value of $\sum_{i=1}^{n} f\left(x_{i}^{*}\right) \Delta x$.

\section{1) Trapezoidal rule}

Suppose that $f$ is continuous over $[a, b]$ and let's consider a partition of the interval $[a, b]$ in $n$-subintervals $a=x_{0}<x_{1}<$ $x_{2}<\cdots<x_{n}=b$ of the same length $\Delta x=\frac{b-a}{n}$.

If in each subinterval $\left[x_{i-1}, x_{i}\right]$ of the partition the minimum and maximum value of the function is $f\left(\alpha_{i}\right)$ and $f\left(\beta_{i}\right)$ respectively, then:

$$
\begin{gathered}
f\left(\alpha_{i}\right) \leq f\left(x_{i-1}\right) \leq f\left(\beta_{i}\right) \\
\mathrm{y} \\
f\left(\alpha_{i}\right) \leq f\left(x_{i}\right) \leq f\left(\beta_{i}\right) .
\end{gathered}
$$

Therefore $2 f\left(\alpha_{i}\right) \leq f\left(x_{i-1}\right)+f\left(x_{i}\right) \leq 2 f\left(\beta_{i}\right)$. So, we get that $f\left(\alpha_{i}\right) \leq \frac{f\left(x_{i-1}\right)+f\left(x_{i}\right)}{2} \leq f\left(\beta_{i}\right)$. Now we apply the IVT corollary exists $x_{i}^{*}$ in the interval $\left[x_{i-1}, x_{i}\right]$ such that $f\left(x_{i}^{*}\right)=$ $\frac{f\left(x_{i-1}\right)+f\left(x_{i}\right)}{2}$. We get the Trapeze rule by the following way:

$$
\begin{aligned}
& f\left(x_{1}^{*}\right)+f\left(x_{2}^{*}\right)+\cdots+f\left(x_{n}^{*}\right)=\frac{f\left(x_{0}\right)+f\left(x_{1}\right)}{2}+\frac{f\left(x_{1}\right)+f\left(x_{2}\right)}{2}+ \\
& \cdots+\frac{f\left(x_{n-1}\right)+f\left(x_{n}\right)}{2} .
\end{aligned}
$$

Also, as $\Delta x=\frac{b-a}{n}$, then

$$
\int_{a}^{b} f(x) d x \cong \sum_{i=1}^{n} f\left(x_{i}^{*}\right) \Delta x=\frac{b-a}{2 n}\left[f\left(x_{0}\right)+2 f\left(x_{1}\right)+2 f\left(x_{2}\right)+\cdots+2 f\left(x_{n-1}\right)+f\left(x_{n}\right)\right]
$$

$=\frac{b-a}{2 n}\left[f\left(x_{0}\right)+2\left[f\left(x_{1}\right)+f\left(x_{2}\right)+\cdots+f\left(x_{n-1}\right)\right]+f\left(x_{n}\right)\right] \cdots \cdots$.

This approximation is known as Trapezoidal Rule

\section{2) Simpson's rule}

Usually Simpson's rule is tested using two subintervals of the same length $\left[x_{i-1}, x_{i}\right]$ and $\left[x_{i}, x_{i+1}\right]$ and passing a parable through three values $f\left(x_{i-1}\right), f\left(x_{1}\right)$ and $f\left(x_{i+1}\right)$ as long as this points are not collinear.

An alternative approach of the Simpson's rule, based on the IVT, allows to make generalizations different from the Simpson 3/8 rules, Boole rules and the fifth and sixth order rule. The new approximation formulas are obtained naturally, since they are simply a certain sum of Riemman and the demonstrations are not that elaborate as the ones that require the rules based on polynomials of interpolation mentioned before. Then, we will deduce Simpson's rule and other rules using means.

Again, suppose that $f$ is continuous over $[\mathrm{a}, \mathrm{b}]$ and consider a partition in $n$-subintervals $a=x_{0}<x_{1}<x_{2}<\cdots<x_{n}=b$ of the same length $\Delta x=\frac{b-a}{n}$

Suppose that $n$ is an even positive integer and for any two consecutive subintervals, $\left[x_{i-1}, x_{i}\right]$ and $\left[x_{i}, x_{i+1}\right]$ consider the interval $\left[x_{i-1}, x_{i+1}\right]$. Now be $f\left(\alpha_{i}\right)$ and $f\left(\beta_{i}\right)$ the minimum and maximum value of the $f$ function in the subinterval $\left[x_{i-1}, x_{i+1}\right]$, then we clearly have that:

$$
f\left(\alpha_{i}\right) \leq f\left(x_{i-1}\right) \leq f\left(\beta_{i}\right)
$$




$$
\begin{gathered}
f\left(\alpha_{i}\right) \leq f\left(x_{i}\right) \leq f\left(\beta_{i}\right) \\
f\left(\alpha_{i}\right) \leq f\left(x_{i+1}\right) \leq f\left(\beta_{i}\right)
\end{gathered}
$$

From here we get

$$
3 f\left(\alpha_{i}\right) \leq f\left(x_{i-1}\right)+f\left(x_{i}\right)+f\left(x_{i+1}\right) \leq 3 f\left(\beta_{i}\right)
$$

From where

$$
f\left(\alpha_{i}\right) \leq \frac{f\left(x_{i-1}\right)+f\left(x_{i}\right)+f\left(x_{i+1}\right)}{3} \leq f\left(\beta_{i}\right)
$$

Applying the IVT corollary, exists $c \in\left[x_{i-1}, x_{i+1}\right]$ such that

$$
f(c)=\frac{f\left(x_{i-1}\right)+f\left(x_{i}\right)+f\left(x_{i+1}\right)}{3}
$$

On the other hand, we know that $c$ is in one of the intervals $\left[x_{i-1}, x_{i}\right]$ or $\left[x_{i}, x_{i+1}\right]$ (or in both).

Case I. If $c$ belongs to the interval $\left[x_{i-1}, x_{i}\right]$, then we do $x_{i}^{*}=$ $c$ and as $x_{i}$ belongs to the interval $\left[x_{i}, x_{i+1}\right]$ we choose $x_{i+1}^{*}=$ $x_{i}$.

Therefore

$$
\begin{array}{r}
\Delta x f\left(x_{i}^{*}\right)+\Delta x f\left(x_{i+1}^{*}\right)=\Delta x\left[f\left(x_{i}^{*}\right)+f\left(x_{i+1}^{*}\right)\right] \\
=\Delta x\left[f(c)+f\left(x_{i}\right)\right] \\
=\Delta x\left[\frac{f\left(x_{i-1}\right)+f\left(x_{i}\right)+f\left(x_{i+1}\right)}{3}+f\left(x_{i}\right)\right] \\
=\Delta x\left[\frac{f\left(x_{i-1}\right)+4 f\left(x_{i}\right)+f\left(x_{i+1}\right)}{3}\right]
\end{array}
$$

Case 2. If $\mathrm{c}$ belongs to the interval $\left[x_{i}, x_{i+1}\right]$, then we choose $x_{i+1}^{*}=c$ and as $x_{i}$ belongs to the interval $\left[x_{i-1}, x_{i}\right]$ we do $x_{i}^{*}=x_{i}$

$$
\begin{gathered}
\Delta x f\left(x_{i}^{*}\right)+\Delta x f\left(x_{i+1}^{*}\right) \\
=\Delta x\left[f\left(x_{i}^{*}\right)+f\left(x_{i+1}^{*}\right)\right]=\Delta x\left[f\left(x_{i}\right)+f(c)\right] \\
=\Delta x\left[f\left(x_{i}\right)+\frac{f\left(x_{i-1}\right)+f\left(x_{i}\right)+f\left(x_{i+1}\right)}{3}\right] \\
=\Delta x\left[\frac{f\left(x_{i-1}\right)+4 f\left(x_{i}\right)+f\left(x_{i+1}\right)}{3}\right]
\end{gathered}
$$

Thereby we see that in any of the two cases we have that

$$
\Delta x f\left(x_{i}^{*}\right)+\Delta x f\left(x_{i+1}^{*}\right)=\Delta x\left[\frac{f\left(x_{i-1}\right)+4 f\left(x_{i}\right)+f\left(x_{i+1}\right)}{3}\right]
$$

Particularly we have that

$$
\begin{aligned}
\Delta x\left[f\left(x_{1}^{*}\right)+f\left(x_{2}^{*}\right)\right] & =\Delta x\left[\frac{f\left(x_{0}\right)+4 f\left(x_{1}\right)+f\left(x_{2}\right)}{3}\right] \\
\Delta x\left[f\left(x_{3}^{*}\right)+f\left(x_{4}^{*}\right)\right] & =\Delta x\left[\frac{f\left(x_{2}\right)+4 f\left(x_{3}\right)+f\left(x_{4}\right)}{3}\right] \\
\Delta x\left[f\left(x_{n-1}^{*}\right)+f\left(x_{n}^{*}\right)\right] & =\Delta x\left[\frac{f\left(x_{n-2}\right)+4 f\left(x_{n-1}\right)+f\left(x_{n}\right)}{3}\right]
\end{aligned}
$$

Therefore, by taking the sum

$\sum_{i=1}^{n} f\left(x_{i}^{*}\right) \Delta x=\Delta x\left[f\left(x_{1}^{*}\right)+f\left(x_{2}^{*}\right)+\cdots+f\left(x_{n-1}^{*}\right)+f\left(x_{n}^{*}\right)\right]$ with $\Delta x=\frac{b-a}{n}$ and we associate two by two $\left[f\left(x_{0}^{*}\right)+\right.$ $\left.f\left(x_{1}^{*}\right)\right]+\left[f\left(x_{2}^{*}\right)+f\left(x_{3}^{*}\right)\right]+\cdots+\left[f\left(x_{n-1}^{*}\right)+f\left(x_{n}^{*}\right)\right] \quad$ we obtain the well-known formula of Simpson's rule, that is to say

$$
\begin{gathered}
\int_{a}^{b} f(x) d x \cong \frac{b-a}{3 n}\left[f\left(x_{0}\right)+4 f\left(x_{1}\right)+2 f\left(x_{2}\right)+4 f\left(x_{3}\right)+\cdots+2 f\left(x_{n-2}\right)\right. \\
\left.+4 f\left(x_{n-1}\right)+f\left(x_{n}\right)\right] \\
=\frac{b-a}{3 n}\left[f\left(x_{0}\right)+4\left[\begin{array}{l}
\left.f\left(x_{1}\right)+f\left(x_{3}\right)+\cdots+f\left(x_{n-1}\right)\right] \\
\left.+2\left[f\left(x_{2}\right)+f\left(x_{4}\right)+\cdots+f\left(x_{n-2}\right)\right]+f\left(x_{n}\right)\right]
\end{array}\right.\right.
\end{gathered}
$$

Notice that the sum $\left[f\left(x_{1}\right)+f\left(x_{3}\right)+\cdots+f\left(x_{n-1}\right)\right]$ does not contain $f\left(x_{t}\right)$ such that $t$ is a multiple of 2 and the sum $\left[f\left(x_{2}\right)+f\left(x_{4}\right)+\cdots+f\left(x_{n-2}\right)\right]$ only contains $f\left(x_{t}\right)$ where $t$ is a multiple of 2 .

Thereby we can write this formula as

$\int_{a}^{b} f(x) d x \cong \frac{b-a}{3 n}\left[f\left(x_{0}\right)+4\left[\sum_{t \text { is not even }}^{t=n-1} f\left(x_{t}\right)\right]+\right.$ $\left.2\left[\sum_{\text {tis iven }}^{t=n-2} f\left(x_{t}\right)\right]+f\left(x_{n}\right)\right] \ldots .(3)$

This approximation is the Simpson's Rule

\section{3) General Rule of Arithmetic Means: $k$ subintervals}

Generalizing the previous procedure to three subintervals [ $\left.x_{i-1}, x_{i}\right],\left[x_{i}, x_{i+1}\right]$ and $\left[x_{i+1}, x_{i+2}\right]$. Again if $f\left(\alpha_{i+1}\right)$ and $f\left(\beta_{i+1}\right)$ the minimum and maximum value of the function $f$ in the subinterval $\left[x_{i-1}, x_{i+2}\right]$, then clearly we have that:

$$
\begin{gathered}
f\left(\alpha_{i+1}\right) \leq f\left(x_{i-1}\right) \leq f\left(\beta_{i+1}\right) \\
f\left(\alpha_{i+1}\right) \leq f\left(x_{i}\right) \leq f\left(\beta_{i+1}\right) \\
f\left(\alpha_{i+1}\right) \leq f\left(x_{i+1}\right) \leq f\left(\beta_{i+1}\right) \\
f\left(\alpha_{i+1}\right) \leq f\left(x_{i+2}\right) \leq f\left(\beta_{i+1}\right)
\end{gathered}
$$

From here we obtain

$$
4 f\left(\alpha_{i+1}\right) \leq f\left(x_{i-1}\right)+f\left(x_{i}\right)+f\left(x_{i+1}\right)+f\left(x_{i+2}\right) \leq 4 f\left(\beta_{i+1}\right)
$$




$$
f\left(\alpha_{i+1}\right) \leq \frac{f\left(x_{i-1}\right)+f\left(x_{i}\right)+f\left(x_{i+1}\right)+f\left(x_{i+2}\right)}{4} \leq f\left(\beta_{i+1}\right)
$$

Now by the IVT exists $c \in\left[x_{i-1}, x_{i+2}\right]$ such that

$$
f(c)=\frac{f\left(x_{i-1}\right)+f\left(x_{i}\right)+f\left(x_{i+1}\right)+f\left(x_{i+2}\right)}{4}
$$

Here we will take three cases

Case 1. If $c$ belongs to the interval $\left[x_{i-1}, x_{i}\right]$, then we do $x_{i}^{*}=$ $c$, as $x_{i}$ belongs to the interval $\left[x_{i}, x_{i+1}\right]$ we choose $x_{i+1}^{*}=x_{i}$, finally as $x_{i+1}$ belongs to the interval $\left[x_{i+1}, x_{i+2}\right]$ we choose $x_{i+2}^{*}=x_{i+1}$.

Thus, we have that:

$$
\begin{aligned}
\Delta x & {\left[f\left(x_{i}^{*}\right)+f\left(x_{i+1}^{*}\right)+f\left(x_{i+2}^{*}\right)\right]=\Delta x\left[f(c)+f\left(x_{i}\right)+f\left(x_{i+1}\right)\right] } \\
& =\Delta x\left[\frac{f\left(x_{i-1}\right)+f\left(x_{i}\right)+f\left(x_{i+1}\right)+f\left(x_{i+2}\right)}{4}+f\left(x_{i}\right)+f\left(x_{i+1}\right)\right] \\
& =\Delta x\left[\frac{f\left(x_{i-1}\right)+5 f\left(x_{i}\right)+5 f\left(x_{i+1}\right)+f\left(x_{i+2}\right)}{4}\right]
\end{aligned}
$$

Case 2. If $c$ belongs to the interval $\left[x_{i}, x_{i+1}\right]$, then we set $x_{i+1}^{*}=c$ and as $x_{i}$ belongs to the interval $\left[x_{i-1}, x_{i}\right]$ we set $x_{i}^{*}=x_{i}$ finally as $x_{i+1}$ belongs to the interval $\left[x_{i+1}, x_{i+2}\right]$ we set $x_{i+2}^{*}=x_{i+1}$.

Thus, we have that:

$$
\begin{aligned}
& \Delta x\left[f\left(x_{i}^{*}\right)+f\left(x_{i+1}^{*}\right)+f\left(x_{i+2}^{*}\right)\right]=\Delta x\left[f\left(x_{i}\right)+f(c)+f\left(x_{i+1}\right)\right] \\
& \quad=\Delta x\left[f\left(x_{i}\right)+\frac{f\left(x_{i-1}\right)+f\left(x_{i}\right)+f\left(x_{i+1}\right)+f\left(x_{i+2}\right)}{4}+f\left(x_{i+1}\right)\right] \\
& =\Delta x\left[\frac{f\left(x_{i-1}\right)+5 f\left(x_{i}\right)+5 f\left(x_{i+1}\right)+f\left(x_{i+2}\right)}{4}\right]
\end{aligned}
$$

Notice that it is exactly the same result as Case $\mathbf{1 .}$

Case 3. If $c$ belongs to the interval $\left[x_{i+1}, x_{i+2}\right]$, then we choose $x_{i+2}^{*}=c$ and as $x_{i}$ belongs to the interval $\left[x_{i-1}, x_{i}\right]$ we set $x_{i}^{*}=x_{i}$ finally as $x_{i+1}$ belongs to the interval $\left[x_{i}, x_{i+1}\right]$ we set $x_{i+1}^{*}=x_{i+1}$.

It is easy to see that again we reach the same result as before, that is to say

$$
\begin{gathered}
\Delta x\left[f\left(x_{i}^{*}\right)+f\left(x_{i+1}^{*}\right)+f\left(x_{i+2}^{*}\right)\right] \\
=\Delta x\left[f\left(x_{i}\right)+f\left(x_{i+1}\right)+\frac{f\left(x_{i-1}\right)+f\left(x_{i}\right)+f\left(x_{i+1}\right)+f\left(x_{i+2}\right)}{4}\right] \\
=\Delta x\left[\frac{f\left(x_{i-1}\right)+5 f\left(x_{i}\right)+5 f\left(x_{i+1}\right)+f\left(x_{i+2}\right)}{4}\right]
\end{gathered}
$$

We could say that the three cases are only one case.
Now, if $n$ is a multiple of 3 and we associate 3 in 3

Particularly we have

$$
\begin{aligned}
& \Delta x\left[f\left(x_{1}^{*}\right)+f\left(x_{2}^{*}\right)+f\left(x_{3}^{*}\right)\right] \\
& =\Delta x\left[\frac{f\left(x_{0}\right)+5 f\left(x_{1}\right)+5 f\left(x_{2}\right)+f\left(x_{3}\right)}{4}\right] \\
& \Delta x\left[f\left(x_{4}^{*}\right)+f\left(x_{5}^{*}\right)+f\left(x_{6}^{*}\right)\right] \\
& =\Delta x\left[\frac{f\left(x_{3}\right)+5 f\left(x_{4}\right)+5 f\left(x_{5}\right)+f\left(x_{6}\right)}{4}\right] \\
& \Delta x\left[f\left(x_{7}^{*}\right)+f\left(x_{8}^{*}\right)+f\left(x_{9}^{*}\right)\right] \\
& =\Delta x\left[\frac{f\left(x_{6}\right)+5 f\left(x_{7}\right)+5 f\left(x_{8}\right)+f\left(x_{9}\right)}{4}\right]
\end{aligned}
$$

Now we sum the three previously equations and we have

$$
\begin{gathered}
\Delta x\left[f\left(x_{1}^{*}\right)+f\left(x_{2}^{*}\right)+f\left(x_{3}^{*}\right)\right]+\Delta x\left[f\left(x_{4}^{*}\right)+f\left(x_{5}^{*}\right)+f\left(x_{6}^{*}\right)\right] \\
+\Delta x\left[f\left(x_{7}^{*}\right)+f\left(x_{8}^{*}\right)+f\left(x_{9}^{*}\right)\right]
\end{gathered}
$$

$=\Delta x\left[\frac{f\left(x_{0}\right)+5 f\left(x_{1}\right)+5 f\left(x_{2}\right)+2 f\left(x_{3}\right)+5 f\left(x_{4}\right)+5 f\left(x_{5}\right)+2 f\left(x_{6}\right)+5 f\left(x_{7}\right)+5 f\left(x_{8}\right)+f\left(x_{9}\right)}{4}\right]$

Notice that it appears $2 f\left(x_{3}\right)$ and $2 f\left(x_{6}\right)$, this is because $f\left(x_{3}\right)$ and $f\left(x_{6}\right)$ appear two times in the numerator.

Continuing like this and grouping this way, setting $\Delta x=\frac{b-a}{n}$ and assuming that $n$ is a multiple of 3 , we get to the formula.

$$
\begin{aligned}
& \int_{a}^{b} f(x) d x \\
& \cong \frac{b-a}{n}\left[\frac{f\left(x_{0}\right)+5 f\left(x_{1}\right)+5 f\left(x_{2}\right)+2 f\left(x_{3}\right)+5 f\left(x_{4}\right)+5 f\left(x_{5}\right)+2 f\left(x_{6}\right)+\cdots+5 f\left(x_{n-1}\right)+f\left(x_{n}\right)}{4}\right] \\
& \int_{a}^{b} f(x) d x \cong \frac{b-a}{4 n}\left[\begin{array}{r}
{[} \\
\left.+5\left(x_{0}\right)+5 f\left(x_{1}\right)+5 f\left(x_{2}\right)+2 f\left(x_{3}\right)+5 f\left(x_{4}\right)+2 f\left(x_{6}\right)+\cdots+5 f\left(x_{n-1}\right)+f\left(x_{n}\right)\right] \\
+
\end{array}\right.
\end{aligned}
$$

Factoring 5 and 2 we get the following expression

$$
\begin{aligned}
\int_{a}^{b} f(x) d x \cong \frac{b-a}{4 n}[ & f\left(x_{0}\right) \\
& +5\left[f\left(x_{1}\right)+f\left(x_{2}\right)+f\left(x_{4}\right)+f\left(x_{5}\right)+\cdots f\left(x_{n-2}\right)\right. \\
& \left.\left.+f\left(x_{n-1}\right)\right]+2\left[f\left(x_{3}\right)+f\left(x_{6}\right) \ldots+f\left(x_{n-3}\right)\right]+f\left(x_{n}\right)\right]
\end{aligned}
$$

Notice that in the sum

$$
\left[f\left(x_{1}\right)+f\left(x_{2}\right)+f\left(x_{4}\right)+f\left(x_{5}\right)+\cdots f\left(x_{n-2}\right)+f\left(x_{n-1}\right)\right]
$$

The terms $f\left(x_{3}\right), f\left(x_{6}\right), \ldots$, which are the $f\left(x_{t}\right)$ where $t$ is a multiple of 3 , does not appear.

Also, notice that the sum

$$
\left[f\left(x_{3}\right)+f\left(x_{6}\right)+\cdots+f\left(x_{n-3}\right)\right]
$$

Only contains the terms of the form $f\left(x_{t}\right)$ where $t$ is a multiple of 3 .

So we can write the formula 


$$
\begin{aligned}
& \int_{a}^{b} f(x) d x \cong \frac{b-a}{4 n} {\left[f\left(x_{0}\right)+5\left[\sum_{t \text { is not multiple of } 3}^{t=n-1} f\left(x_{t}\right)\right]\right.} \\
&\left.+2\left[\sum_{t=3,6,9, \ldots}^{t=n-3} f\left(x_{t}\right)\right]+f\left(x_{n}\right)\right]
\end{aligned}
$$

From these observations we can generalize the previous procedure and consider $k$ consecutive subintervals.

$\left[x_{0}, x_{1}\right],\left[x_{1}, x_{2}\right], \ldots,\left[x_{k-1}, x_{k}\right]$. If $n$ is a multiple of $k$ and $n>k$, then we get a new rule.

$$
\begin{aligned}
\int_{a}^{b} f(x) & d x \cong \frac{b-a}{(k+1) n}\left[f\left(x_{0}\right)+(k+2)\left[f\left(x_{1}\right)+\cdots+f\left(x_{k-1}\right)\right]+\right. \\
& +2 f\left(x_{k}\right)+(k+2)\left[f\left(x_{k+1}\right)+\ldots+f\left(x_{2 k-1}\right)\right]+ \\
& +2 f\left(x_{2 k}\right)+\cdots+(k+2)\left[f\left(x_{n-(k-1)}\right)+\cdots+f\left(x_{n-1}\right)\right]+ \\
& \left.+f\left(x_{n}\right)\right]
\end{aligned}
$$

Regrouping as in the previous examples we can write the formula as:

$\int_{a}^{b} f(x) d x \cong \frac{b-a}{(k+1) n}\left[f\left(x_{0}\right)+(k+2)\left[f\left(x_{1}\right)+\cdots+f\left(x_{k-1}\right)+\right.\right.$ $f\left(x_{k+1}\right)+f\left(x_{k+1}\right)+\ldots+f\left(x_{2 k-1}\right)+f\left(x_{2 k+1}\right)+\cdots+$ $\left.\left.f\left(x_{n-1}\right)\right]+2\left[f\left(x_{k}\right)+f\left(x_{2 k}\right)+\cdots+f\left(x_{n-k}\right)\right]+f\left(x_{n}\right)\right]$

As an alternative way we can write the formula the following way: $\int_{a}^{b} f(x) d x \cong \frac{b-a}{(k+1) n}\left[f\left(x_{0}\right)+(k+2)\left[f\left(x_{1}\right)+\cdots+f\left(x_{k-1}\right)\right]+\right.$

$$
\begin{aligned}
& +2 f\left(x_{k}\right)+(k+2)\left[f\left(x_{k+1}\right)+\ldots+f\left(x_{2 k-1}\right)\right]+ \\
& +2 f\left(x_{2 k}\right)+\cdots+(k+2)\left[f\left(x_{n-(k-1)}\right)+\cdots+f\left(x_{n-1}\right)\right]+ \\
& \left.+f\left(x_{n}\right)\right]
\end{aligned}
$$

$\int_{a}^{b} f(x) d x \cong \frac{b-a}{(k+1) n}\left[f\left(x_{0}\right)+(k+2)\left[\sum_{t}^{t=n-1}\right.\right.$ is not multiple of $\left.k f\left(x_{t}\right)\right]+$ $\left.2\left[\sum_{t=k, 2 k, 3 k, . .}^{t=n-k} f\left(x_{t}\right)\right]+f\left(x_{n}\right)\right] \ldots(4)$

We will call it General Formula of the Arithmetic Means. (GFAM)

Notice that when $k=1$ we have a special case of the formula (GFAM) because formally the sum

$$
\sum_{t \text { is not multiple of } k}^{t=n-1} f\left(x_{t}\right)
$$

does not have addends since this sum is taken without multiples of $k=1$, but the multiples of $k=1$ are all the positives integers, there are no addends in this sum, therefore, this sum is zero.

$$
\sum_{t \text { is not multiple of } k}^{t=n-1} f\left(x_{t}\right)=0
$$

Therefore, when $k=1$ the formula (GFAM) takes the following form:

$$
\begin{gathered}
\int_{a}^{b} f(x) d x \cong \frac{b-a}{(k+1) n}\left[f\left(x_{0}\right)+(k+2)\left[\sum_{t \text { is not multiple of } k}^{t=n-1} f\left(x_{t}\right)\right]\right. \\
\left.+2\left[\sum_{t \text { is multiple of } k}^{t=n-k} f\left(x_{t}\right)\right]+f\left(x_{n}\right)\right] \\
\int_{a}^{b} f(x) d x \cong \frac{b-a}{(1+1) n}\left[f\left(x_{0}\right)+(k+2)[0]\right. \\
\left.+2\left[\sum_{t \text { is multiple of } k}^{t=n-k} f\left(x_{t}\right)\right]+f\left(x_{n}\right)\right] \\
=\frac{b-a}{2 n}\left[f\left(x_{0}\right)+2\left[\sum_{t \text { is multiple of } k}^{t=n-k} f\left(x_{t}\right)\right]+f\left(x_{n}\right)\right] \\
=\frac{b-a}{2 n}\left[f\left(x_{0}\right)+2\left[f\left(x_{1}\right)+f\left(x_{2}\right)+\cdots+f\left(x_{n-1}\right)\right]+f\left(x_{n}\right)\right]
\end{gathered}
$$

Which is the formula of the Trapezoidal rule (see (2)).

Now we divide in two consecutive subintervals, that is to say $k=2$ and we substitute that value in (GFAM), then we obtain the formula

$$
\begin{aligned}
& \int_{a}^{b} f(x) d x \cong \frac{b-a}{(2+1) n}\left[f\left(x_{0}\right)+(2+2)\left[f\left(x_{1}\right)+f\left(x_{2+1}\right)+f\left(x_{2(2)+1}\right)+\cdots+\right.\right. \\
& \left.\left.f\left(x_{n-1}\right)\right]+2\left[f\left(x_{2}\right)+f\left(x_{2(2)}\right)+\cdots+f\left(x_{n-2}\right)\right]+f\left(x_{n}\right)\right]= \\
& \int_{a}^{b} f(x) d x \cong \frac{b-a}{3 n}\left[f\left(x_{0}\right)+4\left[f\left(x_{1}\right)+f\left(x_{3}\right)+f\left(x_{5}\right)+\cdots+f\left(x_{n-1}\right)\right]+\right. \\
& \left.2\left[f\left(x_{2}\right)+f\left(x_{4}\right)+\cdots+f\left(x_{n-2}\right)\right]+f\left(x_{n}\right)\right]
\end{aligned}
$$

Which is the Simpson's rule (see (3)).

Notice that if $k=n$, we have another special case of the formula (GFAM) because the sum

$$
\sum_{t=k, 2 k, 3 k, \ldots}^{t=n-k} f\left(x_{t}\right)
$$

Formally starts at $t=k=n>0$ and ends in $t=n-k=$ $k-k=0$, therefore, this sum does not have addends, so this sum is 0 .

$$
\sum_{t=k, 2 k, 3 k, \ldots}^{t=n-k} f\left(x_{t}\right)=0
$$

Therefore, the formula (GFAM) that written as

$$
\begin{array}{r}
\int_{a}^{b} f(x) d x \cong \frac{b-a}{(n+1) n}\left[f\left(x_{0}\right)+(n+2)\left[\sum_{t \text { is not multiple of } k}^{t=n-1} f\left(x_{t}\right)\right]\right. \\
\left.+2\left[\sum_{t=k, 2 k, 3 k, . .}^{t=n-k} f\left(x_{t}\right)\right]+f\left(x_{n}\right)\right]
\end{array}
$$




$$
\begin{array}{r}
=\frac{b-a}{(n+1) n}\left[f\left(x_{0}\right)+(n+2)\left[\sum_{t \text { is not multiple of } k}^{t=n-1} f\left(x_{t}\right)\right]+2[0]\right. \\
\left.+f\left(x_{n}\right)\right] \\
=\frac{b-a}{(n+1) n}\left[f\left(x_{0}\right)+(n+2)\left[\sum_{t \text { is not multiple of } k}^{t=n-1} f\left(x_{t}\right)\right]+f\left(x_{n}\right)\right] \\
=\frac{b-a}{(n+1) n}\left[f\left(x_{0}\right)+(n+2)\left[f\left(x_{1}\right)+\cdots+f\left(x_{n-1}\right)\right]+f\left(x_{n}\right)\right]
\end{array}
$$

Example 1. Here is a table to calculate $\int_{1}^{2} e^{1 / x} d x$ using the General Formula of the Arithmetic Means with $k=3$ subintervals and using $n=12$.

TABLE I

CALCULATIONS IN EXCEL

\begin{tabular}{cccc}
\multicolumn{4}{c}{ CALCULATIONS IN EXCEL } \\
\hline \hline$x_{i}$ & $f\left(x_{i}\right)$ & $w_{i}$ & $w_{i} f\left(x_{i}\right)$ \\
\hline 1 & 2.7183 & 1 & 2.7183 \\
1.0833 & 2.517 & 5 & 12.5851 \\
1.1667 & 2.3564 & 5 & 11.7821 \\
1.25 & 2.2255 & 2 & 4.4511 \\
1.3333 & 2.117 & 5 & 10.585 \\
1.4167 & 2.0256 & 5 & 10.1282 \\
1.5 & 1.9477 & 2 & 3.8955 \\
1.5833 & 1.8806 & 5 & 9.4029 \\
1.6667 & 1.8221 & 5 & 9.1106 \\
1.75 & 1.7708 & 2 & 3.5416 \\
1.8333 & 1.7254 & 5 & 8.627 \\
1.9167 & 1.685 & 5 & 8.4248 \\
2 & 1.6487 & 1 & 1.6487 \\
\hline \hline
\end{tabular}

$$
\begin{aligned}
& \sum_{i=1}^{n} w_{i} f\left(x_{i}\right)=96.9007 \\
& \int_{1}^{2} e^{1 / x} d x=\frac{2-1}{3(12)} \sum_{i=1}^{12} w_{i} f\left(x_{i}\right)=2.0188
\end{aligned}
$$

As it is known, the value of $\int_{1}^{2} e^{1 / x} d x$ does not have an exact decimal representation. Nevertheless, the approximate result can be compared with the value $\int_{1}^{2} e^{1 / x} d x=2.0200586244$, obtained with Wolfram Alpha to 10 decimals.

\section{B. Other formulas not based on arithmetic mean}

\section{1) Geometric Mean}

Suppose now that $f$ is continuous over $[a, b]$ and no negative in the interval $\left[x_{i-1}, x_{i}\right]$. Be $\alpha_{i}$ and $\beta_{i}$ the minimum and maximum value of $f$ in the interval $\left[x_{i-1}, x_{i}\right]$ respectively, as $\alpha_{i} \geq 0$, then we have that $\alpha_{i}^{2} \leq f\left(x_{i-1}\right) f\left(x_{i}\right) \leq \beta_{i}^{2}$ from we get that

$$
a_{i} \leq \sqrt{f\left(x_{i-1}\right) f\left(x_{i}\right)} \leq \beta_{i} .
$$

By the IVT we can use the value $x_{i}^{*}$ in the interval $\left[x_{i-1}, x_{i}\right]$ such that $f\left(x_{i}^{*}\right)=\sqrt{f\left(x_{i-1}\right) f\left(x_{i}\right)}$. Therefore, if we set $\Delta x=$ $\frac{b-a}{n}$ then we get to the Geometric Mean Rule.

$$
\begin{aligned}
& \int_{a}^{b} f(x) d x \cong \sum_{i=1}^{n} f\left(x_{i}^{*}\right) \Delta x=\Delta x\left[\sqrt{f\left(x_{0}\right) f\left(x_{1}\right)}+\sqrt{f\left(x_{1}\right) f\left(x_{2}\right)}+\cdots+\sqrt{f\left(x_{n-1}\right) f\left(x_{n}\right)}\right] \\
= & \frac{b-a}{n}\left[\sqrt{f\left(x_{0}\right) f\left(x_{1}\right)}+\sqrt{f\left(x_{1}\right) f\left(x_{2}\right)}+\cdots+\sqrt{f\left(x_{n-1}\right) f\left(x_{n}\right)}\right] \ldots(5)
\end{aligned}
$$

We call this approximation Geometric Mean Rule.

\section{2) Harmonic Mean}

Suppose now that $f$ in continuous over $[a, b]$ and positive in the interval $\left[x_{i-1}, x_{i}\right]$. Be $\alpha_{i}$ and $\beta_{i}$ the minimum and maximum value of $f$ in the interval $\left[x_{i-1}, x_{i}\right]$ respectively, then $\alpha_{i} \leq f\left(x_{i-1}\right) \leq \beta_{i}$ and as $f$ is not negative, then

$$
\alpha_{i} f\left(x_{i}\right) \leq f\left(x_{i-1}\right) f\left(x_{i}\right) \leq \beta_{i} f\left(x_{i}\right)
$$

Analogously as $\alpha_{i} \leq f\left(x_{i}\right) \leq \beta_{i}$, then

$$
\alpha_{i} f\left(x_{i-1}\right) \leq f\left(x_{i}\right) f\left(x_{i-1}\right) \leq \beta_{i} f\left(x_{i-1}\right)
$$

Adding up both inequalities we have that

$$
\alpha_{i} f\left(x_{i-1}\right)+\alpha_{i} f\left(x_{i}\right) \leq 2 f\left(x_{i-1}\right) f\left(x_{i}\right) \leq \beta_{i} f\left(x_{i-1}\right)+\beta_{i} f\left(x_{i}\right)
$$

So

$$
\alpha_{i}\left[f\left(x_{i-1}\right)+f\left(x_{i}\right)\right] \leq 2 f\left(x_{i-1}\right) f\left(x_{i}\right) \leq \beta_{i}\left[f\left(x_{i-1}\right)+f\left(x_{i}\right)\right]
$$

Therefore

$$
\alpha_{i} \leq \frac{2 f\left(x_{i-1}\right) f\left(x_{i}\right)}{f\left(x_{i-1}\right)+f\left(x_{i}\right)} \leq \beta_{i}
$$

By the IVT we can use the value $x_{i}^{*}$ in the interval $\left[x_{i-1}, x_{i}\right]$ such that $f\left(x_{i}^{*}\right)=\frac{2 f\left(x_{i-1}\right) f\left(x_{i}\right)}{f\left(x_{i-1}\right)+f\left(x_{i}\right)}$. Therefore, we get to the Harmonic Mean Rule. (remember that $f$ is positive, so no quotient is undetermined)

$\int_{a}^{b} f(x) d x \cong 2 \Delta x\left[\frac{f\left(x_{0}\right) f\left(x_{1}\right)}{f\left(x_{0}\right)+f\left(x_{1}\right)}+\frac{f\left(x_{1}\right) f\left(x_{2}\right)}{f\left(x_{1}\right)+f\left(x_{2}\right)}+\cdots+\frac{f\left(x_{n-1}\right) f\left(x_{n}\right)}{f\left(x_{n-1}\right)+f\left(x_{n}\right)}\right] \quad \cdots$ (6) We call this approximation Harmonic Mean Rule.

Notice that in the Geometric Mean and Harmonic Mean the request that it be positive in the interval $\left[x_{i-1}, x_{i}\right]$ is not a great restriction, as we can take the intervals where the function $f$ is positive and where is negative. In the intervals where $f$ is negative, we only change the sign so these rules can be applied and we give the result the sign that corresponds.

\section{3) Any convex combination}

The rules of numerical integration deducted in this subsection use basically the IVT. Taking this idea we can generalize the rules of numerical integration the following way:

Let's consider as before a continuous function $f$ in the interval $[a, b]$ and we split it in equal $n$-subintervals

$$
a=x_{0}<x_{1}<x_{2}<\cdots<x_{n}=b \text {, así } \Delta x=\frac{b-a}{n} \text {. }
$$


a) For each subinterval $\left[x_{i-1}, x_{i}\right]$ consider $\alpha_{i}$ and $\beta_{i}$ the maximum and minimum value of $f$.

b) For each $1 \leq i \leq n$, be $r_{i}$ a real number such that $0 \leq r_{i} \leq 1$ then

$$
\alpha_{i} \leq \alpha_{i}+r_{i}\left(\beta_{i}-\alpha_{i}\right)=\left(1-r_{i}\right) \alpha_{i}+r_{i} \beta_{i} \leq\left(1-r_{i}\right) \beta_{i}+r_{i} \beta_{i}=\beta_{i}
$$

Therefore

$$
\alpha_{i} \leq\left(1-r_{i}\right) \alpha_{i}+r_{i} \beta_{i} \leq \beta_{i}
$$

By the IVT exists $x_{i}^{*} \in\left[x_{i-1}, x_{i}\right]$ such that

$$
f\left(x_{i}^{*}\right)=\alpha_{i}+r_{i}\left(\beta_{i}-\alpha_{i}\right) \text {. }
$$

From here we obtain the rule

$\sum_{i=1}^{n} f\left(x_{i}^{*}\right) \Delta x=\frac{b-a}{n} \sum_{i=1}^{n} f\left(x_{i}^{*}\right)=\frac{b-a}{n} \sum_{i=1}^{n}\left[\left(1-r_{i}\right) \alpha_{i}+r_{i} \beta_{i}\right]$

\section{Applications}

Next, we consider $r_{i}=r$ for each $1 \leq i \leq n$, then

$$
\sum_{i=1}^{n} f\left(x_{i}^{*}\right) \Delta x=\frac{b-a}{n} \sum_{i=1}^{n}\left[(1-r) \alpha_{i}+r \beta_{i}\right] \ldots
$$

And we present 3 application cases of (6).

Case I. Suppose that $f$ is monotonously increasing in the interval $[a, b]$; then $\alpha_{i}=f\left(x_{i-1}\right)$ and $\beta_{i}=f\left(x_{i}\right)$. Taking $r=$ $\frac{1}{2}$ then (7) becomes the Trapeze rule (2).

$$
\begin{gathered}
\sum_{i=1}^{n} f\left(x_{i}^{*}\right) \Delta x=\frac{b-a}{n} \sum_{i=1}^{n}\left[\frac{\alpha_{i}+\beta_{i}}{2}\right] \\
=\frac{b-a}{n}\left[\sum_{i=1}^{n} \frac{f\left(x_{i-1}\right)+f\left(x_{i}\right)}{2}\right]
\end{gathered}
$$

Notice that if $f$ is monotonously decreasing, then $\alpha_{i}=f\left(x_{i}\right)$ and $\beta_{i}=f\left(x_{i-1}\right)$.

$$
\begin{gathered}
\sum_{i=1}^{n} f\left(x_{i}^{*}\right) \Delta x=\frac{b-a}{n} \sum_{i=1}^{n}\left[\frac{\alpha_{i}+\beta_{i}}{2}\right] \\
=\frac{b-a}{n}\left[\sum_{i=1}^{n} \frac{f\left(x_{i}\right)+f\left(x_{i-1}\right)}{2}\right]
\end{gathered}
$$

Again, we have the Trapeze rule.

Case II. Suppose that $f$ is monotonously increasing in the interval $[a, b]$; then $\alpha_{i}=f\left(x_{i-1}\right)$ and $\beta_{i}=f\left(x_{i}\right)$. Therefore (2) takes the following form

$$
\begin{aligned}
\sum_{i=1}^{n} f\left(x_{i}^{*}\right) \Delta x & =\frac{b-a}{n}\left[\sum_{i=1}^{n}(1-r) f\left(x_{i-1}\right)+r f\left(x_{i}\right)\right] \\
& =\frac{b-a}{n}\left[r\left[f\left(x_{n}\right)-f\left(x_{0}\right)\right]+\sum_{i=1}^{n} f\left(x_{i-1}\right)\right]
\end{aligned}
$$

$$
\begin{array}{r}
=\frac{b-a}{n}\left[r[f(b)-f(a)]+\sum_{i=1}^{n} f\left(x_{i-1}\right)\right] \\
=(b-a)\left[\frac{r}{n}[f(b)-f(a)]+\frac{1}{n} \sum_{i=1}^{n} f\left(x_{i-1}\right)\right]
\end{array}
$$

Notice that the term $\frac{1}{n} \sum_{i=1}^{n} f\left(x_{i-1}\right)$ is the average value of the values $f\left(x_{0}\right), f\left(x_{2}\right), \ldots, f\left(x_{n-1}\right)$.

Case III. Suppose that $f$ es monotonously decreasing in the interval $[a, b]$, then $\alpha_{i}=f\left(x_{i}\right)$ and $\beta_{i}=f\left(x_{i-1}\right)$. Therefore (7) takes the form

$$
\begin{aligned}
& \sum_{i=1}^{n} f\left(x_{i}^{*}\right) \Delta x=\frac{b-a}{n} \sum_{i=1}^{n}\left[(1-r) f\left(x_{i}\right)+r f\left(x_{i-1}\right)\right] \\
&=\frac{b-a}{n}\left[r\left[f\left(x_{0}\right)-f\left(x_{n}\right)\right]+\sum_{i=1}^{n} f\left(x_{i}\right)\right] \\
&=\frac{b-a}{n}\left[r[f(a)-f(b)]+\sum_{i=1}^{n} f\left(x_{i}\right)\right] \\
&=(b-a)\left[\frac{r}{n}[f(a)-f(b)]+\frac{1}{n} \sum_{i=1}^{n} f\left(x_{i}\right)\right] \ldots \text { (9) }
\end{aligned}
$$

Notice that the term $\frac{1}{n} \sum_{i=1}^{n} f\left(x_{i}\right)$ is the average value of the values $f\left(x_{1}\right), f\left(x_{2}\right), \ldots, f\left(x_{n}\right)$.

We finish this work calculating the integral $\int_{1}^{2} e^{\frac{1}{x}} d x$. Be $1 r$ to the Golden proportion and taking $n=12$. We notice that $f(x)=e^{\frac{1}{x}}$ is a monotonously decreasing function in the interval $[1,2]$

$$
\begin{array}{r}
\int_{1}^{2} e^{\frac{1}{x}} d x \cong \sum_{i=1}^{n} f\left(x_{i}^{*}\right) \Delta x=\frac{b-a}{n}\left[\frac{2}{1+\sqrt{5}}[f(1)-f(2)]+\sum_{i=1}^{n} f\left(x_{i}\right)\right] \\
=\frac{2-1}{10}\left(\frac{2}{1+\sqrt{5}}\left[e^{1}-e^{\frac{1}{2}}\right]+\sum_{i=1}^{12} e^{\frac{1}{1+\frac{i}{10}}}\right) \cong 2.0384
\end{array}
$$

\section{RESULTS}

Next, we present a comparative table of the results obtained by calculating $\int_{1}^{2} e^{\frac{1}{x}} d x$.

TABLE II

VALUES OF $\int_{1}^{2} e^{\frac{1}{x}} d x$ OBTAINED BY DIFFERENT METHODS

\begin{tabular}{ccc}
\hline \hline Method & Values & Errors \\
\hline Trapeze & 2.0214 & $0.066 \%$ \\
Simpson & 2.0201 & $0.002 \%$ \\
Simpson3 & 2.0188 & $-0.064 \%$ \\
Simpson(k=n) & 2.0089 & $-0.555 \%$ \\
Geometric Mean & 2.0208 & $0.037 \%$ \\
Arithmetic Mean & 2.0202 & $0.009 \%$ \\
Golden proportion & 2.0384 & $0.900 \%$ \\
Wolfram & 2.02006 & Reference \\
\hline \hline
\end{tabular}


The calculation of the formulas for an error in terms of the derivatives of the function is a pending task.

With the use of the Riemann sums and the Intermediate Value Theorem, the numerical integration formulas that already existed were generalized, such as the Middle Point rule, the Trapezoidal rule and the Simpson rule. With this generalization we obtained new formulas for numerical integration that we call Arithmetic Mean, Golden proportion and Geometric Mean.

\section{CONCLUSIONS}

This method shows that the known numerical integration rules can be generalized into new numerical integration formulas. These new rules can approximate the result of an acceptably defined integral.

\section{REFERENCES}

[1] Stewart J. Cálculo Trascendentes tempranas, Cruz Manca, Santa Fe, Mexico City: CENGAGE Learning (2013)

[2] Zill D. G. y Wright W. S. Cálculo de una variable, Desarrollo, Santa Fe: Mc Graw Hill (2011)

[3] Purcell E. J., Rigdon S. E. y Varberg D., Cálculo, Naucalpan de Juárez, Edo. de México: PEARSON Educación. (2007)

[4] Larson R. E., Hosttler R.P.,Edwards B.H. Cálculo y Geometría Analítica, Sixth edition, Vol 1. Spain: Mc Graw Hill Interamericana (1999).

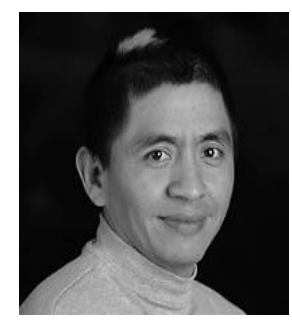

Jaime Castro Pérez was born in Mexico City, Mexico. He received the Ph.D. degree from Universidad Nacional Autónoma de México in 1992. He has been a member of the Science Department at Tecnológico de Monterrey, Campus Ciudad de México since 1991. He currently works as a full-time research professor in the area of non-commutative algebra and has 14 research papers and 4 books published. Dr. Castro is a member of the American Mathematical Society (AMS), the American Mathematical Review (AMR), the Sociedad Matemática Mexicana (SMM) and the Sistema Nacional de Investigadores (SNI), holding a level 1.

ORCID: https://orcid.org/0000-0001-7195-9268

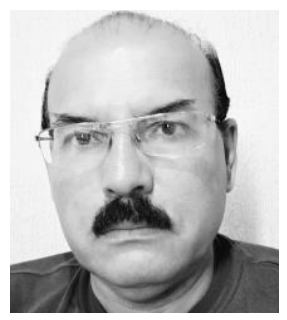

Andrés González Nucamendi was born in Mexico. He received the Ph.D. degree from Universidad Autónoma Metropolitana, México in 2009. He has been a member of the Science Department at Tecnológico de Monterrey, Campus Ciudad de México since 1998 as full-time professor. He has published 3 books and several papers about Economy and Education. His research interest includes Learning Analytics and the use of Haptics Devises in Physics.
ORCID: https://orcid.org/0000-0001-5707-2767

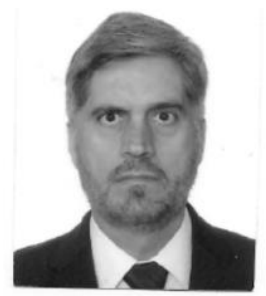

Gerardo Pioquinto Aguilar Sánchez was born in Mexico City. He received the Ph.D. degree from Instituto Tecnologico y de Estudios Superiores de Monterrey in 2005. He has been a member of the Science Department at Tecnológico de Monterrey, Campus Ciudad de México since 1993 as fulltime professor. He has been co-author of several books. ORCID: https://orcid.org/0000-0001-8712-6711 